\title{
Development of Glyceryl Monostearate Based Ciprofloxacin Hydrochloride Sustained Release Matrix Tablet: an In vitro Study
}

\section{Susmita Laila, Tasnuva Haque, Md. Mesbah Uddin Talukder, Ishtiaq Ahmed, Muhammad Rashedul Islam and Md. Habibur Rahman}

\author{
Department of Pharmaceutical Technology, Faculty of Pharmacy, Univerity of Dhaka, \\ Dhaka-1000. Bangladesh
}

\begin{abstract}
In this present study an attempt has been made to evaluate glyceryl monostearate (GMS) as a rate retarding material to sustain the release ciprofloxacin hydrochloride from the matrix tablet. The solubility of ciprofloxacin hydrochloride was studied. The physical parameters of the prepared tablets were also evaluated. Release kinetics of ciprofloxacin hydrochloride from this sustained release matrix was studied in $0.1 \mathrm{~N} \mathrm{HCl}$ using United States Pharmacopoeia type-II dissolution apparatus (paddle method). The effect of polymer load, drug load, hydroxylpropylmethylcellulose to compensate glyceryl monostearate (GMS) and different release modifiers were examined. It was observed that the release rate of drug was retarded with the increasing concentration of GMS. The release data were treated in different fashion to identify the release mechanism and it was revealed with few exception that, when GMS is used as single polymer, release of active drug from the prepared matrix tablet appeared to follow the first order kinetics and showed the tendency to follow Korsmeyer model when HPMC 15 cps was used along with GMS. Using release enhancers the release pattern were fitted to first order kinetics. From the $f_{2}$ values it can be concluded that the release pattern of P-2, D-1, H-2 and H-3 are similar to P-1, whereas the formula of P-1, D-2 and $\mathrm{H}-1$ were same. MDT values were found to be increased with the increasing amount of polymer (GMS).
\end{abstract}

Key words: Glyceryl monostearate, ciprofloxacin $\mathrm{HCl}$, sustained release matrix, dissolution studies.

\section{INTRODUCTION}

Ciprofloxacin $\mathrm{HCl}$ (CIP) is chemically 1Cyclopropyl-6-fluoro-4-oxo-7-(piperazin-1-yl)-1,4dihydroquinoline-3-carboxylic acid hydrochloride. It is soluble in water, slightly soluble in methanol, very slightly soluble in ethanol, practically insoluble in acetone, in ethyl acetate and in methylene chloride. ${ }^{1}$ Ciprofloxacin is a fluorinated quinolone having broad antimicrobial activity and is effective after oral or parenteral administration. Side effects with the use of ciprofloxacin are relatively few and development of

Correspondence to:

Md. Habibur Rahman

Phone: 88-07175028872; Fax: 88-02-8615583

E-mail: hrahman82@yahoo.com

Dhaka Univ. J. Pharm. Sci. 8(1): 81-88, 2009 (June) resistance by microbes is not rapid..$^{2}$ It is used in urinary tract infection, sexually transmitted diseases, and infections of the gut, respiratory tract, bones, and soft tissues. A few cases of ciprofloxacin-induced photosensitivity, hypersensitivity, anaphylaxis, vasculitis, erythema multiforme, Stevens-Johnson syndrome, or toxic epidermal necrolysis have been reported so far. ${ }^{2-4}$

In the last two decades, sustained-release dosage forms have made significant progress in terms of clinical efficacy and patient compliance. ${ }^{5}$ Preparation of drug-embedded matrix tablet that involves the direct compression of a blend of drug, retardant material and additives is one of the least complicated approaches for delivering drug in a temporal pattern 
into the systemic circulation. The matrix system is commonly used for manufacturing sustained-release dosage forms because it makes such manufacturing easy. ${ }^{6}$ Glyceryl monostearate (GMS) is octadecanoic acid, monoester with 1,2,3-propane-triol. ${ }^{7}$ It has been used as a matrix ingredient for a biodegradable, implantable, controlled release dosage form. ${ }^{8}$ Nonionic cellulose ethers, and most frequently hydroxypropyl methylcellulose (HPMC, hypromellose) have been widely studied for their applications in oral sustained release (SR) systems. ${ }^{9}$ When in contact with water, HPMC hydrates rapidly and forms a gelatinous barrier layer around the tablet. The rate of drug release from HPMC matrix is dependent on various factors such as type of polymer, drug, polymer/drug ratio, particle size of drug and polymer, and the type and amount of fillers used in the formulation. ${ }^{10}$

In this present study, the effect of different GMS load, drug load, effect of HPMC 15 cps to compensate the decreasing content of GMS and the effect of some release enhancers on the release rate of CIP from the matrix tablets were evaluated using different models (Zero order, First order, Higuchi's model, Korsmeyer's model and similarity factor; $f_{2}$ ).

\section{MATERIALS AND METHOD}

Ciprofloxacin $\mathrm{HCl}$ (active drug) was purchased from Tasc pharmaceuticals Ltd. (India), GMS and HPMC 15 cps (polymers) were from Merck KGaA (Germany) and Shin Etsu Chemical Company Ltd. (Japan) respectively. Other excipients, such as lactose, $\mathrm{NaCl}$, dextrose, citric acid and $\mathrm{NaHCO}_{3}$ were obtained from The Lactose Co. of Newzealand Ltd. (Newzealand), Remo Chemicals Ltd. (Bangladesh), Pure Chemical Co. Ltd. (Thailand), Merck KGaA (Germany) and BDH (United Kingdom) respectively. Potassium dihydrogen phosphate of Merck (Germany), $\mathrm{HCl}$ (35\%) of Merck (Germany) and purified water of Research laboratory (Bangladeh) were used as the reagents. Among the instruments, vernier caliper of Erweka (Germany), Shimadzu UV Spectrophotometer (Japan), hardness tester and dissolution tester were from Erweka (Germany),
Pharmatest disintegration tester (Germany), mini drum blender of Cadmach Machinery (India), fribility tester of Logan (USA), Hanna $\mathrm{pH}$ meter (Portugal), stainless steel sieve (Bangladesh) and Manestry 16 station compression machine (England) were used.

Preparation of matrix tablet. Wet granulation method was chosen to prepare the matrix tablet of CIP. At first all the formulation materials (given in Table 1), except lubricants (magnesium stearate and aerosil), were sieved through 30-mesh stainless steel screen, mix well and then granulated with water. Then they are dried in oven at $60^{\circ} \mathrm{C}$ temperature for an hour and passed through 24 mesh stainless steel screen (oversized granules were passed with the aid of stone crushing). Then they are taken into a mini drum blender along with the lubricants and mix well for 3 minutes. The blend is then compressed with a constant compression pressure at specified weight using 16-station Manesty compression machine. Stainless steel die and punch with $12.7 \mathrm{~mm}$ diameter were used to compress the tablets. For each formulation 100 tablets were prepared. Formulations with different percentages of GMS were coded as P-1 to P-3, with different concentrations of drug were coded as D-1 to D-3, H-1 to $\mathrm{H}-3$ were coded to indicate the use of HPMC to compensate the decreasing order of GMS, E-1 to E-3 contained different types of release enhancers.

Solubility test of CIP in three media. For the measurement of solubility of CIP, $1 \mathrm{~g}$ of drug was taken in a test tube and the quantity of media (water, $0.1 \mathrm{~N} \mathrm{HCl}$ and $\mathrm{pH} 5.8$ phosphate buffer) required to make the drug soluble was recorded.

Evaluation of CIP matrix tablets. The prepared tablets were evaluated for their hardness, thickness and disintegration time using Erweka hardness tester, Erweka vernier caliper and Pharmatest disintegration tester were used. Six tablets of each formulation were taken.

Drug content assay. Drug content of the sample solution i.e. the quantity of the drug release was determined by Spectrophotometric analysis and the absorbance measured at $276 \mathrm{~nm}$ by using Shimadzu 
UV spectrophotometer. In each time respective dissolution media was used as blank. For each value of absorbance, the concentration of the corresponding solution was calculated by using equation of the standard curve and then the amount of drug of each vessel was determined. Finally the \% of drug release was calculated using the drug content of each batch. The average \% release of two tablets was calculated. The average percent release of drug was then plotted against time.

In vitro dissolution study in $0.1 \mathrm{~N}$ HCl media (pH 1.2). The dissolution of the prepared matrix tablets was studied according to FDA Recommended Dissolution Methods ${ }^{11}$ by using Erweka dissolution tester (Paddle method), with a rotation of $50 \mathrm{rpm}$ at $37 \pm 0.5^{\circ} \mathrm{C}$ placing 1 -liter dissolution media $(0.1 \mathrm{~N}$ $\mathrm{HCl})$ in each vessel. Three tablets from each batch were taken into three vessels. It means the experiment was carried out in triplicate and each time we ran two batches. After each specified time intervals $5 \mathrm{ml}$ of the dissolution media was withdrawn from each vessel for assay of drug content and was replaced by a fresh portion of medium of same volume. The collected sample was then filtered through Whattman no. 41 filter paper. Then $1 \mathrm{ml}$ filtrate was taken into a $50 \mathrm{ml}$ volumetric flask and diluted up to the mark with dissolution media. The absorbances of the samples were measured at $276 \mathrm{~nm}$ by using Shimadzu UV spectrophotometer. Now the percent release of drug was calculated from the measured absorbance.

Release kinetics. The suitability of several equations that are reported in the literature to identify the mechanisms for the release of naproxen was tested with respect to the release data. The data were evaluated according to the following equations:

Zero-order model: ${ }^{12}$

$$
\begin{aligned}
& \mathbf{M}_{\mathbf{t}}=\mathbf{M}_{\mathbf{0}}+\mathbf{K}_{\mathbf{0}} \mathbf{t} \ldots \ldots \ldots \ldots \ldots \ldots \ldots \text { (1) } \\
& \text { Higuchi model: }{ }^{13,14} \\
& \mathbf{M}_{\mathbf{t}}=\mathbf{M}_{\mathbf{0}}+\mathbf{K}_{\mathbf{H}} \mathbf{t}^{0.5} \ldots \ldots \ldots \ldots \ldots \ldots . \ldots(\mathbf{2}) \\
& \text { Korsmeyer-Peppas model: }{ }^{15,16} \\
& \mathbf{M}_{\mathbf{t}}=\mathbf{M}_{\mathbf{0}}+\mathbf{K} \mathbf{t}^{\mathbf{n}} \ldots \ldots \ldots \ldots \ldots \ldots . .(3)
\end{aligned}
$$

Where, $\mathrm{M}_{\mathrm{t}}$ is the amount of drug dissolved in time $t, \mathrm{M}_{0}$ is the initial amount of drug, $\mathrm{K}_{0}$ is the zeroorder release constant, $\mathrm{K}_{\mathrm{H}}$ is the Higuchi rate constant, $\mathrm{K}$ is a release constant, and $\mathrm{n}$ is the release exponent that characterizes the mechanism of drug release.

First order model: ${ }^{17}$

$$
\log C=\log C o-k t / 2.303 \text {. }
$$

Where, $\mathrm{C}=$ cumulative percent of drug release at time $\mathrm{t}, \mathrm{Co}=$ the initial concentration of drug at $\mathrm{t}=0$ and $\mathrm{k}=$ first order rate constant.

To characterize the drug release rates in different experimental conditions, mean dissolution time (MDT) was calculated from dissolution according to Mockel and Lippold ${ }^{19}$ using the following equation:

$$
\text { MDT }=\mathbf{n} \text { X }\left(\mathbf{K}^{-1 / n}\right) /(\mathbf{n}+\mathbf{1}) \text {. }
$$

Where, $\mathrm{n}$ is the release exponent and $\mathrm{K}$ is the kinetic constant calculated from Equation 3.

The similarity factor used to compare the difference of dissolution profiles of the test matrix tablets is given below:

$$
f_{2}=50 \log \left\{\left[1+\frac{1}{n} \sum_{t=1}^{n}\left(R_{t}-T_{t}\right)^{2}\right]^{-0.5} \times 100\right\}
$$

where $R_{t}$ and $T_{t}$ are the percentages of drug dissolved at each time point for the test and reference products, respectively and $n$ is the number of dissolution samples taken. ${ }^{20,21}$

Statistics. To compare the means of all release data and to assess statistical significance between them, either one-way repeated measures analysis of variance (ANOVA) performed at the 5\% significance level, using SPSS software, version 16.0.

\section{RESULTS AND DISCUSSION}

The solubility study was carried out for powder of CIP using three different media (purified water, $0.1 \mathrm{~N} \mathrm{HCl}$ and $\mathrm{pH} 5.8$ phosphate buffer). It is observed from table 3 , that CIP is more soluble in $\mathrm{pH}$ 5.8 phosphate buffer $(1 \mathrm{gm} / 80 \mathrm{ml})$ than in purified water $(1 \mathrm{gm} / 110 \mathrm{ml})$ and $0.1 \mathrm{~N} \mathrm{HCl}(1 \mathrm{gm} / 170 \mathrm{ml})$. 
The prepared tablets were evaluated for their physical parameters. The hardness values ranged from 5.9-7.6 kg, the thickness ranged from 4.9 to
$6.08 \mathrm{~mm}$ and disintegration time 6.5 minutes to greater than 45 minutes (Table 4).

Table 1. Formulation of different matrix tablets of ciprofloxacin HCl.

\begin{tabular}{|c|c|c|c|c|c|c|c|c|c|}
\hline \multirow{2}{*}{$\begin{array}{l}\text { Formulation } \\
\text { Code }\end{array}$} & \multicolumn{9}{|c|}{ Ingredients (mg/tablet) } \\
\hline & CIP & GMS & $\begin{array}{c}\text { HPMC } \\
15 \text { cps } \\
\end{array}$ & $\mathrm{NaCl}$ & Dextrose & $\begin{array}{c}\text { Citric } \\
\text { acid }+\mathrm{Na}_{2} \mathrm{CO}_{3}\end{array}$ & MgS & Aerosil & Total weight \\
\hline$* \mathrm{P}-1$ & 582 & 200 & - & - & - & - & 5 & 3 & 790 \\
\hline $\mathrm{P}-2$ & 582 & 150 & - & - & - & - & 5 & 3 & 740 \\
\hline $\mathrm{P}-3$ & 582 & 100 & - & - & - & - & 5 & 3 & 690 \\
\hline D-1 & 500 & 200 & - & - & - & - & 5 & 3 & 708 \\
\hline$* \mathrm{D}-2$ & 582 & 200 & - & - & - & - & 5 & 3 & 790 \\
\hline D-3 & 665 & 200 & - & - & - & - & 5 & 3 & 873 \\
\hline H-1 & 582 & 200 & - & - & - & - & 5 & 3 & 790 \\
\hline $\mathrm{H}-2$ & 582 & 150 & 50 & - & - & - & 5 & 3 & 790 \\
\hline H-3 & 582 & 100 & 100 & - & - & - & 5 & 3 & 790 \\
\hline E-1 & 582 & 150 & - & 37.5 & - & - & 5 & 3 & 777.5 \\
\hline E-2 & 582 & 150 & - & - & 37.5 & - & 5 & 3 & 777.5 \\
\hline E-3 & 582 & 150 & - & - & - & 37.5 & 5 & 3 & 777.5 \\
\hline
\end{tabular}

*P-1, D-2 and H-1 have the same formula. CIP = ciprofloxacin HCl, MgS = magnesium stearate.

From the dissolution results it was observed that P-1, D-2 and H-1 showed same release pattern and released 32.82\% CIP at the end of 8 hours. P-2 and P-3 released about $75.25 \%$ drug after 8 hours and $99.68 \%$ drug after 2 hours respectively. D-1 and D-3 showed $26.75 \%$ and $60.17 \%$ release at the end of 8 hours. $\mathrm{H}-2$ and $\mathrm{H}-3$ released about $35.91 \%$ and $39.63 \%$ CIP after 8 hours. E-1 released $98.97 \%$ drug at 3 hours, $98.99 \%$ drug at 1.5 hours and E-3 released $88.21 \%$ drug at the end of 8 hours (Figure-1). Considering P-1 as reference, D-2 and $\mathrm{H}-1$ showed $f_{2}$ value of $100 \%, \mathrm{P}-2, \mathrm{D}-1, \mathrm{H}-2$ and $\mathrm{H}-3$ showed $f_{2}$ values of $97.924,68.401,81.042$ and 70.845 respectively (Table 5).

Table 2. Release mechanism with variation of $n^{*}$ values $^{17}$

\begin{tabular}{ccc}
\hline $\mathrm{N}$ value & Mechanism & $\begin{array}{c}\mathrm{dM}_{\mathrm{t}} / \mathrm{d}_{\mathrm{t}} \\
\text { dependence }\end{array}$ \\
\hline $\mathrm{n}<0.5$ & Quasi-Fickian diffusion & $\mathrm{T}^{0.5}$ \\
0.5 & Fickian diffusion & $\mathrm{T}^{0.5}$ \\
$0.5<\mathrm{n}<1.0$ & Anomolous (non-Fickian) & $\mathrm{t}^{\mathrm{n}-1}$ \\
& diffusion \\
1 & non-Fickian case II & Zero order \\
$\mathrm{n}>1.0$ & non-Fickian super case II & $\mathrm{t}^{\mathrm{n}-1}$ \\
\hline
\end{tabular}

Table 3. Solubility of CIP in three different dissolution media

\begin{tabular}{lc}
\hline Media & $\begin{array}{c}\text { Volume (ml) of media } \\
\text { required to dissolve } 1 \mathrm{~g} \text { of } \\
\text { CIP }\end{array}$ \\
\hline Purified water & 110 \\
$0.1 \mathrm{~N} \mathrm{HCl}$ & 170 \\
pH 5.8 phosphate buffer & 80 \\
\hline
\end{tabular}

Table 4. Physical parameters of GMS based CIP matrix tablets (values are expressed as mean)

\begin{tabular}{cccc}
\hline $\begin{array}{c}\text { Formulation } \\
\text { code }\end{array}$ & $\begin{array}{c}\text { Hardness } \\
(\mathrm{kg})\end{array}$ & $\begin{array}{c}\text { Thickness } \\
(\mathrm{mm})\end{array}$ & $\begin{array}{c}\mathrm{DT} \\
(\mathrm{min})\end{array}$ \\
\hline P-1/D-2/H-1 & 6.300 & 6.080 & $>45$ \\
P-2 & 6.400 & 5.060 & 21.500 \\
P-3 & 5.900 & 4.900 & 12 \\
D-1 & 6.100 & 5.010 & $>45$ \\
D-3 & 6.500 & 6.210 & $>45$ \\
H-2 & 6.400 & 5.800 & $>45$ \\
H-3 & 6.700 & 5.540 & $>45$ \\
E-1 & 7.600 & 5.100 & 7.500 \\
E-2 & 7.100 & 5.460 & 6.500 \\
E-3 & 6.800 & 5.500 & 6.500 \\
\hline
\end{tabular}

DT =disintegration time, Formulation of P-1, D-2 and H-1 are same.

CIP is a water soluble drug with pKa of 4. That's why table 3 showed that its solubility was highest in pH 5.8 phosphate buffer $(1 \mathrm{gm} / 80 \mathrm{ml})$. Tablets of different formulations prepared according to Table 1 , 
were subjected to various tests such as hardness, thickness, disintegration time, friability, potency determination and in vitro dissolution testing. All the formulations showed uniform thickness. Good uniformity in drug content was found among all different batches of tablets and the percent drug content was more than $98 \%$. All of the formulations showed high hardness value (5.9 kg to $7.6 \mathrm{~kg}$ ). Tablet hardness is not an absolute indicator of strength. ${ }^{22}$ Another measure of a tablet's strength is friability. Conventional compressed tablets that lose less than $1 \%$ of their weight are generally considered acceptable. In the present study, the percentage friability for all the formulations was below $1 \%$, indicating that the friability is within the prescribed limits (Table 4). ${ }^{22}$

Table 5. Kinetic values obtained from various plot of CIP-based matrix tablets.

\begin{tabular}{|c|c|c|c|c|c|c|c|}
\hline \multirow{2}{*}{ Formulation } & \multirow{2}{*}{$\frac{\text { Zero order }}{\mathrm{R}^{2}}$} & \multirow{2}{*}{$\frac{\text { Higuchi }}{\mathrm{R}^{2}}$} & \multirow{2}{*}{$\frac{\text { First order }}{\mathrm{R}^{2}}$} & \multicolumn{2}{|c|}{ Korsmeyer } & \multirow[t]{2}{*}{ MDT } & \multirow[t]{2}{*}{$f_{2}$} \\
\hline & & & & $\mathrm{R}^{2}$ & $\mathrm{n}$ & & \\
\hline P-1 & 0.899 & 0.965 & 0.974 & 0.990 & 0.671 & 16.026 & REF \\
\hline P-2 & 0.843 & 0.980 & 0.994 & 0.976 & 0.687 & 4.225 & 97.924 \\
\hline P-3 & 0.547 & 0.917 & 0.994 & 0.854 & 0.258 & 0.340 & 4.163 \\
\hline D-1 & 0.880 & 0.981 & 0.977 & 0.996 & 0.608 & 26.353 & 68.401 \\
\hline D-2 & 0.899 & 0.965 & 0.974 & 0.990 & 0.671 & 16.026 & 100.000 \\
\hline D-3 & 0.911 & 0.960 & 0.990 & 0.993 & 0.727 & 6.002 & 36.710 \\
\hline $\mathrm{H}-1$ & 0.899 & 0.965 & 0.974 & 0.990 & 0.671 & 16.026 & 100.000 \\
\hline $\mathrm{H}-2$ & 0.903 & 0.966 & 0.979 & 0.991 & 0.661 & 16.849 & 81.042 \\
\hline $\mathrm{H}-3$ & 0.943 & 0.946 & 0.990 & 0.995 & 0.744 & 5.407 & 70.845 \\
\hline E-1 & 0.665 & 0.944 & 0.967 & 0.880 & 0.578 & 0.835 & 7.681 \\
\hline E-2 & 0.657 & 0.938 & 0.998 & 0.937 & 0.212 & 0.248 & 3.880 \\
\hline E-3 & 0.576 & 0.956 & 0.971 & 0.915 & 0.571 & 2.704 & 17.122 \\
\hline
\end{tabular}

$\mathrm{R}^{2}=$ Correlation coefficient, $\mathrm{n}=$ release exponent, $\mathrm{MDT}=$ mean dissolution time and $f_{2}=$ similarity factor $(\mathrm{P}-1$ was reference standard).

Effect of single GMS polymer. The in vitro drug release characteristics were studied in simulated gastric and intestinal fluids for a period of $10 \mathrm{hrs}$ using USP XXVIII dissolution apparatus 2 (paddle method). As P-1, D-2 and $\mathrm{H}-1$ have the same formula, they showed same release pattern up to 8 hours. Formulations from P-1 to P-3 were prepared using different percentages of GMS (25.32\%, 20.27\% and $14.49 \%$ respectively). Form the release pattern it was observed that P-3 released $99.68 \%$ drug at 8 hours as this formulation contains least amount of GMS, whereas P-1 and P-2 released 32.82\% and $75.25 \%$ drug at 8 hours. From this scenario it can be concluded that GMS at $25 \%$ and $20 \%$ concentrations shows sustained release up to 8 hours.

Effect of drug load. Formulations of D-1 to D-3 were prepared to evaluate the effect of drug content on their release pattern (at 70.62\%, 73.67\% and $76.17 \%$ drug content respectively but the GMS content was fixed). D-1 to D-3 showed 26.63\%, $32.82 \%$ and $60.17 \%$ drug release at 8 hours. The amount of GMS used in this formulation was 200 $\mathrm{mg}$, indicating the drug entrapping capacity at this amount is highest that's why the release rate of drug was increased with the increasing drug content.

Effect of HPMC 15 cps to compensate the decreasing content of GMS. Formulations of $\mathrm{H}-1$ to H-3 were prepared to evaluate the effect of HPMC $15 \mathrm{cps}$ to compensate the decreased GMS load on the release pattern of CIP (at GMS: HPMC of 100:0, 75:25 and 50:50). H-1 to H-3 showed 32.82\%, $35.91 \%$ and $39.63 \%$ drug release at the end of 8 hours. It is observed that the percent release was very slightly increased as the HPMC load increased or GMS load decreased. From this result, it can be stated that GMS has slight more rate retarding action on release pattern of CIP than HPMC 15cps but both are capable to retard the release of CIP up to 8 hours.

Effect of some release enhancers. Formulations of E-1 to E-3 were prepared to evaluate the effect of some individual release enhancers on the release pattern of CIP. E-1 to E-3 contained single $\mathrm{NaCl}$, 
single dextrose and both citric acid and $\mathrm{Na}_{2} \mathrm{CO}_{3}$ at $4.823 \%$ concentration. In case of $\mathrm{E}-1 \mathrm{NaCl}$ was used as osmotic agent. Due to its osmotic effect it gave an osmotic pressure on the surrounding matrix and the matrix brust out and released the drug very promptly (98.97\% at 3 hours). Dextrose was used in E-2 as channel former. Due to its free solubility it allowed the penetration of the media in to the matrix and thus increased the release of drug (98.99\% at 1.5 hours). Combination of citric acid and sodium carbonate were used in formulation E-3. Sodium carbonate was used as a gas generating agent. The effect of citric acid on drug release profile and floating properties were investigated. Since the $\mathrm{pH}$ of stomach is elevated under fed condition ( 3.5), citric acid was incorporated in the formulation to provide as acidic medium for sodium carbonate. Moreover, citric acid has a stabilizing effect on the formulations. Although all these release enhancers were incorporated in to formulations to slightly increase the release of CIP from the matrix, it had been seen that individually all the release enhancers totally brust out the matrix in $0.1 \mathrm{~N} \mathrm{HCl}$. Therefore, the release enhancers failed to produce a sustained action and were not suitable for GMS based matrix.

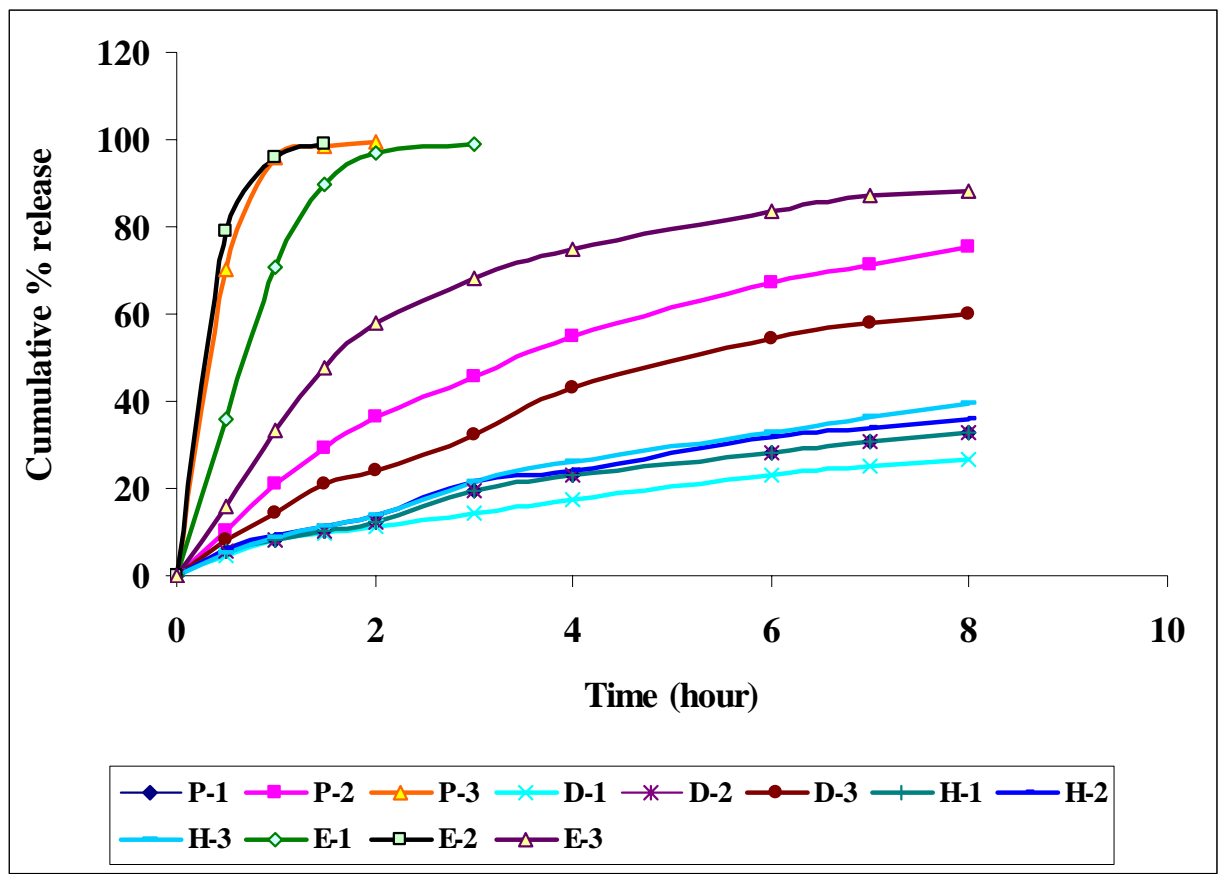

Figure 1. Zero order release kinetics of CIP to evaluate the effect of GMS, drug load, HPMC 15cps and individual release enhancers on the prepared matrix tablets.

From the output of one way repeated measures ANOVA, it was observed that the test of within subject effect showed $\mathrm{p}$ value $=0.000$, indicating the release pattern of drug of different formulation differ significantly in respect of time. The multiple comparisons (Bonferroni and Dunnett) were also carried out. Dunett $t$ tests treat one group as a control and compare all other groups against it (Figure 1). The paired comparison of the eleven groups with the control group showed different result. When P-1 was control group, $\mathrm{D}-2$ and $\mathrm{H}-1$ gave $\mathrm{p}$ value $=1.000$ and
$\mathrm{H}-2$ gave $\mathrm{p}=0.082$, indicating no significant difference among these groups. Similarly considering P-3 as control group, E-2 showed similarity with it (p = 1.000). When D-2 was control group, P-1, H-1, H-2 $(p=1.000)$ and $\mathrm{H}-3(\mathrm{p}=0.132)$ were similar with it. If $\mathrm{H}-1$ was control group, $\mathrm{P}-1$ and $\mathrm{D}-2$ (p 1.000) didn't differ from it. When $\mathrm{H}-2$ was control group, D2 and H-3 (p = 0.000) were similar; when H-3 was control group, $\mathrm{H}-2(\mathrm{p}=1.000)$ and $\mathrm{D}-2(\mathrm{p}=0.132)$ were similar; When E-2 was control group, P-3 was similar to it $(\mathrm{p}=1.000)$. The other formulations 
differed much from each other in terms of release pattern $(\mathrm{p}<0.05)$.

Considering P-1 as reference standard, it is observed from table 5 that the release pattern of D-2 and $\mathrm{H}-1$ are same $\left(f_{2}=100\right)$ to $\mathrm{P}-1$, as these three have same formulation. Whereas P-2, D-1, H-2 and $\mathrm{H}-3$ have $f_{2}$ values within range of 50 to 100 , meaning their release pattern similar to P-1.

During data modeling, it was observed from table 5 that most of the formulations (P-1, D-1 to D-3 and $\mathrm{H}-1$ to $\mathrm{H}-3$ ) were fitted to Korsmeyer equation with $\mathrm{n}$ values between 0.5 to 1 , indicating the probable release mechanism from the matrix tablets were anomalous (non-Fickian) or diffusion-erosion coupled. Rest of the formulations (P-2, P-3, E-1 to E3 ) were best fitted with First order release kinetics. No release patterns were fitted to Zero order or Highchi model.

MDT is used to characterize the drug release rate from the dosage form and the retarding efficacy of the polymer. A higher MDT indicates a higher drugretarding ability of the polymer and vice versa. The MDT value was found to be a function of polymer loading. Table 5 shows that the higher the polymer level, the higher the value of MDT. These findings were in accordance with that of Reza et al. ${ }^{23}$ They investigated the effect of plastic, hydrophilic, and hydrophobic types of polymers; their content level; and drugs of different aqueous solubility values on MDT. The studies showed that a direct relationship could be found with MDT value and polymer loading irrespective of drug and polymer type, and that this relationship was linear.

\section{CONCLUSION}

GMS based CIP matrix tablets were prepared at concentration level of $25.32 \%, 20.27 \%$ and $14.49 \%$ respectively. GMS at $14.49 \%$ concentration was not found to be rate retarding. The different mount of drug load (D-1 to D-3) released the drug up to 8 hours. The percent release was very slightly increased as the HPMC load increased or GMS load decreased (from H-1 to H-3). From this result, it can be stated that GMS has slight more rate retarding action on release pattern of CIP than HPMC 15cps but both are capable to retard the release of CIP up to 8 hours. Different release enhancer containing formulation showed no statistically significant difference of the release patterns among E-1 to E-3, though these formulations were not sustained at all. From the $f_{2}$ values it can be concluded that the release pattern of p-2, D-1, H-2 and H-3 are similar to P-1, whereas the formula of $\mathrm{P}-1, \mathrm{D}-2$ and $\mathrm{H}-1$ were same. MDT values were found to be increased with the increasing amount of polymer (GMS).

\section{ACKNOWLEDGEMENTS}

The authors are thankful to Eskayef Bangladesh Limited for providing laboratory facilities.

\section{REFERENCES}

1. The United States Pharmacopoea 27, NF 25. 2007. United States Pharmacopoeial Convention Inc, Rockville, MD. 20852, U.S.A. pp. 1756.

2. William, A. and Petri, Jr. 2001. In: Goodman and Gilman's. The pharmacological basis of therapeutics (Hardman, J.G. and Limbird, L.E., Eds.), Mc Graw Hill, New York, pp. 1179.

3. Breathnach, S.M. 2004. In: Rook's textbook of dermatology ( $7^{\text {th }}$ ed.), (Burns, T., Breathnach, S. and Cox, N., Eds.), Black Well Publishing, , Vol 4, pp. 744.

4. Alastair, J.J. 2001. In: Harrisons Principles of Internal Medicine (15 $5^{\text {th }}$ ed.), (Wald, B., Fauci and Kasper, Eds.), McGraw Hill, Singapore, Vol. 1, pp. 433.

5. Merkus, F.W.H.M.. 1986. In: Rate- Controlled Drug Administration and Action (Struyker-Boudier, H.A.J. Eds.), CRC Press, Boca Raton, FL, USA, pp. 15-47.

6. Cardinal, J.R. 1984. In: Medical Applications of Controlled Release (Langer, R.S. and Wise, D.L. Eds.), CRC Press, Boca Raton, FL, USA, pp 41-67.

7. Kibbe, A.H. 2000. Hand book of pharmaceutical excipients. $\left(3^{\text {rd }}\right.$ ed.) American Pharmaceutical Association, Pharmaceutical press, Washington, D.C, U.S.A. pp. 225227.

8. Peri, D., Bogdansky, S. Allababidi, S. and Shah, J.C. 1994. Development of an implantable, biodegradable, controlled drug delivery system for local antibiotic therapy. Drug Dev Indian Pharm. 20, 1341-1352.

9. Rajabi-Siahboomi, A.R. and Jordan, M.P. 2000. Slow release HPMC matrix systems. Eur Pharm Rev. 5, 21-23. 
10. Levina, M., Ali, R. and Sihaboomi, R. 2004. The Influence of Excipients on Drug Release from Hydroxypropyl Methylcellulose Matrices. J. Pharm. Sci. 93, 2746-2753.

11. U.S.Food and Drug Administration, Centre for drug evaluation and research, FDA recommended dissolution methods, updated at September 24, 2008. available at: http://www.accessdata.fda.gov/scripts/cder/dissolution/dsp_S earchResults_Dissolutions.cfm?PrintAll=1.

12. Donbrow, M. and Samuelov, Y. 1980. Zero order drug delivery from double-layered porous films: release rate profiles from ethylcellulose, hydroxypropylcellulose and polyethylene glycol mixtures. J Pharm Pharmacol. 32, 463470 .

13. Higuchi, T. 1961. Rate of release of medicaments from ointment bases containing drugs in suspension. J. Pharm. Sci. 50, 874-875.

14. Higuchi, T. 1963. Mechanism of sustained-action medication: theoretical analysis of rate of release of solid drugs dispersed in solid matrices. J. Pharm. Sci. 52, 11451149.

15. Korsmeyer, R.W., Gurny, R., Doelker, E.M., Buri, P. and Peppas, N.A. 1983. Mechanism of solute release from porous hydrophilic polymers. Int. J. Pharm. 15, 25-35.

16. Peppas, N.A. 1985. Analysis of Fickian and non-Fickian drug release from polymers. Pharm. Acta. Helv. 60, 110-111.

17. Merchant, H.A., Shoaib, H.M., Tazeen, J. and Yousuf, R.I. 2006. Once-Daily tablet formulation and in vitro release evaluation of Cefpodoxime using Hydroxypropyl Methylcellulose: A Technical note. AAPS Pharm. Sci. Tech. 7, Article 78.
18. Basak, S.C., Reddy, B.M.J. and Mani, K.P.L. 2006. Formulation and release behaviour of sustained release ambroxol hydrochloride HPMC matrix tablets. Indian $J$. Pharm. Sci. 68, 594-598.

19. Mockel, J.E. and Lippold, B.C. 1993. Zero-order release from hydrocolloid matrices. Pharm. Res. 10, 1066-1070.

20. CDER. Center for Drug Evaluation and Research, Guidance for Industry, Dissolution Testing of Immediate Release Solid Oral Dosage, 1997. Available at: http://www.fda.gov/cder/ Guidance/1713bp1.pdf. Accessed: September 19, 2006.

21. EMEA. European Agency for the Evaluation of Medicinal Products, Human Medicines Evaluation Unit, Note for Guidance on Quality of Modified Release Products: (A) Oral Dosage Forms; (B) Transdermal Dosage Forms; Section I (Quality), CPMP/QWP/604/96 (1999). Available at: http://www.emea.eu.int/pdfs/human/qwp/060496en.pdf. Accessed: September 19, 2006.

22. Banker, G.S. and Anderson, L.R. 1987. In: The Theory and Practice of Industrial Pharmacy (Lachman, L., Liberman, H.A. and Kanig, J.L. Eds.). Varghese Publishing House, Mumbai, India. Chapter 11, pp. 293-345.

23. Reza, M.S., Quadir, M.A. and Haider, S.S. 2003. Comparative evaluation of plastic, hydrophobic and hydrophilic polymers as matrices for controlled-release drug delivery. J. Pharm. Pharm. Sci. 6, 282-291. 